\title{
Dexmedetomidine during total knee arthroplasty performed under spinal anesthesia decreases opioid use: a randomized-controlled trial
}

\section{Réduction de la consommation d'opiö̈des grâce à l'administration de dexmédétomidine pendant une arthroplastie totale du genou réalisée sous rachianesthésie: une étude randomisée contrôlée}

\author{
Ian A. Chan, MD · Jurgen G. Maslany, MD • \\ Kyle J. Gorman, MD • Jennifer M. O'Brien, PhD • \\ William P. McKay, MD \\ Received: 12 July 2015/Revised: 18 October 2015/Accepted: 24 January 2016/Published online: 29 January 2016 \\ (C) Canadian Anesthesiologists' Society 2016
}

\begin{abstract}
Background It remains unclear whether the opioidsparing effects of dexmedetomidine seen in patients undergoing general anesthesia are reproducible in patients undergoing spinal anesthesia. We hypothesized that the administration of intravenous dexmedetomidine for sedation during total knee arthroplasty under spinal anesthesia would decrease postoperative morphine consumption in the first $24 \mathrm{hr}$ following surgery.

Methods We conducted this prospective double-blind randomized-controlled trial in 40 patients (American Society of Anesthesiologists physical status I-III) undergoing total knee arthroplasty with a standardized spinal anesthetic. Patients were randomized to receive either a dexmedetomidine loading dose of $0.5 \mu \mathrm{g} \cdot \mathrm{kg}^{-1}$ over ten minutes, followed by an infusion of $0.5 \mu \mathrm{g} \cdot \mathrm{kg} \cdot \mathrm{hr}{ }^{-1}$ for the duration of the surgery, or a normal saline loading dose and an infusion of an equivalent volume. The primary outcome was the consumption of morphine delivered via patientcontrolled analgesia in the first $24 \mathrm{hr}$ following surgery.

Results The mean (SD) cumulative morphine at $24 \mathrm{hr}$ in the dexmedetomidine group was 29.2 (11.2) mg compared with 61.2 (17.2) $\mathrm{mg}$ in the placebo group (mean difference,
\end{abstract}

I. A. Chan, MD $(\varangle) \cdot$ J. M. O’Brien, PhD · W. P. McKay, MD Department of Anesthesiology, RUH, University of

Saskatchewan, G525-103 Hospital Drive, Saskatoon,

SK S7N 0W8, Canada

e-mail: Ian.chan@usask.ca

J. G. Maslany, MD · K. J. Gorman, MD

Department of Anesthesiology, University of Saskatchewan, Regina, SK, Canada
$32.0 \mathrm{mg} ; 95 \%$ confidence interval, 22.7 to $41.2 ; P<$ 0.001). In the dexmedetomidine group, there was a delay in the time to first analgesic request $(P=0.003)$ and $a$ reduction in the mean morphine use at six and $12 \mathrm{hr}$ following surgery (both $P<0.001$ ).

Conclusions Dexmedetomidine was associated with a significant decrease in morphine use in the first $24 \mathrm{hr}$ following total knee arthroplasty. Our study shows that an intraoperative infusion of dexmedetomidine for sedation in patients receiving spinal anesthesia can produce postoperative analgesic effects. This offers another potential adjunct in the multimodal pain management of these patients. This trial was registered at ClinicalTrials.gov (identifier NCT02026141).

\section{Résumé}

Contexte Nous ne savons pas si les effets de réduction de la consommation d'opiö̈des qu'on observe lors de l'administration de dexmédétomidine aux patients subissant une anesthésie générale s'appliquent également chez les patients subissant une rachianesthésie. Nous avons émis l'hypothèse que l'administration de dexmédétomidine par voie intraveineuse pour la sédation pendant une arthroplastie totale $d u$ genou sous rachianesthésie réduirait la consommation postopératoire de morphine au cours des premières $24 \mathrm{~h}$ après la chirurgie.

Méthode Nous avons réalisé cette étude randomisée contrôlée prospective à double insu chez 40 patients (statut physique I-III selon l'American Society of Anesthesiologists) subissant une arthroplastie totale $d u$ genou avec un anesthésique rachidien standardisé. Les patients ont été randomisés à recevoir soit une dose de 
charge de dexmédétomidine de $0,5 \mu \mathrm{g} \cdot \mathrm{kg}^{-1}$ sur une période de 10 minutes, suivie par une perfusion de $0,5 \mu \mathrm{g} \cdot \mathrm{kg} \cdot \mathrm{h}^{-1}$ pour la durée de la chirurgie, ou une dose de charge de sérum physiologique et une perfusion de volume équivalent. Le critère d'évaluation principal était la consommation de morphine administrée par analgésie contrôlée par le patient au cours des premières $24 h$ suivant la chirurgie.

Résultats Ladose cumulative moyenne (ÉT) de morphine consommée à 24 h dans le groupe dexmédétomidine était de 29,2 (11,2) mg, par rapport à 61,2 (17,2) mg dans le groupe placebo (différence moyenne, 32,0 $\mathrm{mg}$; intervalle de confiance $95 \%, 22,7$ à 41,2; $P<0,001)$. Dans le groupe dexmédétomidine, on a observé un délai jusqu'au moment de première demande d'analgésique $(P=0,003)$ et une réduction de l'utilisation moyenne de morphine à six et 12 $h$ après la chirurgie (les deux $P<0,001$ ).

Conclusion La dexmédétomidine a été associée à une réduction significative de la consommation de morphine au cours des premières $24 \mathrm{~h}$ suivant une arthroplastie totale $d u$ genou. Notre étude montre qu'une perfusion peropératoire de dexmédétomidine pour la sédation de patients recevant une rachianesthésie peut avoir des effets analgésiques postopératoires. Voici donc un autre adjuvant potentiel à la prise en charge multimodale de la douleur de ces patients. Cette étude est enregistrée au ClinicalTrials.gov (identifiant NCT02026141).

Patients receiving spinal anesthesia for surgical procedures often request sedation to alleviate anxiety. ${ }^{1}$ Anesthesiologists must balance patient satisfaction $v s$ the risk of respiratory depression associated with oversedation. A review of closed claims has revealed that respiratory depression from oversedation has caused catastrophic adverse events such as brain damage and death. ${ }^{2}$ Dexmedetomidine, an alpha-2 adrenergic agonist, may be ideally suited to provide sedation during surgery as it offers sedation and analgesia without causing significant respiratory depression. ${ }^{3}$ Compared with frequently used sedatives for procedural sedation (e.g., propofol and midazolam), use of dexmedetomidine resulted in less hypoxemia and increased patient satisfaction. ${ }^{4,5} \mathrm{~A}$ recent meta-analysis also showed improved patient sedation when dexmedetomidine was used during burn procedures. ${ }^{6}$

The analgesic properties of dexmedetomidine may also be beneficial, especially for procedures with significant postoperative pain. ${ }^{7}$ Patients sensitive to the respiratory depressant effects of opioids, such as the elderly or patients with obstructive sleep apnea, may also benefit. ${ }^{8,9}$ The use of intravenous dexmedetomidine for sedation during spinal anesthesia has been studied to some extent, evidenced by its prolonging effect on the duration of sensory and motor block. ${ }^{10}$ A delayed time to first analgesic request was observed in patients undergoing transurethral prostatic resection with spinal anesthesia. ${ }^{11}$ Despite the significant decreases seen following general anesthesia, there is a lack of randomized-controlled trials (RCTs) studying the effects of dexmedetomidine on opioid consumption after spinal anesthesia. ${ }^{12}$

To investigate a potential dexmedetomidine-mediated opioid-sparing effect after spinal anesthesia, we studied opioid requirements of patients undergoing total knee arthroplasty performed under spinal anesthesia -a common operation associated with severe postoperative pain. ${ }^{13,14}$ We hypothesized that sedation with dexmedetomidine during total knee arthroplasty under spinal anesthesia would decrease postoperative morphine consumption during the first $24 \mathrm{hr}$ after surgery.

\section{Methods}

In December 2013, the University of Saskatchewan Biomedical Research Ethics Board gave approval for this single-centre randomized double-blind placebo-controlled parallel-group trial. This project was completed at our tertiary care hospital where approximately 700 total knee replacements are performed annually. Inclusion criteria were adults aged 18-85 yr, American Society of Anesthesiologists (ASA) physical status class I-III, and scheduled for elective unilateral primary total knee arthroplasty under spinal anesthesia. Exclusion criteria included patients with relative contraindications to dexmedetomidine (e.g., allergy, heart block, and significant renal and hepatic impairment), patients with contraindications to morphine or spinal anesthesia, patients preferring general anesthesia, and patients taking narcotics.

The primary outcome was the consumption of morphine delivered via a patient-controlled analgesia (PCA) pump (LifeCare PCA ${ }^{\mathrm{TM}}$ Infusion System, Hospira, Lake Forest, IL, USA) in the first $24 \mathrm{hr}$ following surgery. Secondary outcomes included morphine consumption at six and $12 \mathrm{hr}$ postoperatively, time to first analgesic request via PCA, resting visual analogue scale (VAS) $[(0-10)$ where $0=$ no pain, $10=$ worst imaginable pain] scores at six, 12 , and 24 $\mathrm{hr}$, discharge readiness time from the postanesthesia care unit (PACU), patient satisfaction with their analgesia in the first $24 \mathrm{hr}$, hemodynamic and respiratory changes intraoperatively and in the PACU, and opioid-related adverse effects (i.e., nausea, vomiting, pruritus) in the first $24 \mathrm{hr}$. All the outcomes were pre-specified prior to the start of the trial; however, the research team did not update the protocol at clinicaltrials.gov prior to the study in order to reflect all these non-primary outcome decisions. 
Prior to entering the operating room, a member of the research team recruited the patients and obtained written informed consent. A computerized random number generator (www.random.org) was used to randomize the patients to either the dexmedetomidine or the placebo group in a 1:1 ratio. Access to the random number sequence and preparation of the series of sealed numbered envelopes was entrusted to a research coordinator not involved in patient recruitment, clinical care, or data collection. The patient, anesthesiologist, surgeon, and research team member involved with the patient were blinded to the group allocation. Once a patient was enrolled in the study, an anesthesiologist, who was not involved in the project or patient care, prepared a syringe (containing either normal saline or dexmedetomidine) according to the instructions provided in the sealed numbered envelope. The anesthesiologist then provided this numbered syringe to the attending anesthesiologist involved in the patient's care.

Prior to entering the operating room, all patients were familiarized with the VAS and instructed on the use of the PCA pump. They were instructed to press the PCA demand button if their pain was $\geq 4$ on the VAS.

All patients received oral premedication with acetaminophen $975 \mathrm{mg}$ and naproxen $500 \mathrm{mg}$ as well as an intravenous bolus of Ringer's Lactate $500 \mathrm{~mL} 30 \mathrm{~min}$ prior to their scheduled operation time.

In the operating room, electrocardiography, noninvasive blood pressure, and pulse oximetry monitors were applied. In the dexmedetomidine group, patients received a loading dose of intravenous dexmedetomidine $0.5 \mu \mathrm{g} \cdot \mathrm{kg}^{-1}$ over ten minutes, followed by an infusion of $0.5 \mu \mathrm{g} \cdot \mathrm{kg} \cdot \mathrm{hr}^{-1}$ delivered by a Medfusion ${ }^{\circledR} 3500$ infusion pump (Smiths Medical, St. Paul, MN, USA). In the placebo group, patients received a loading dose and infusion of the equivalent volume of normal saline. Oxygen was delivered to all patients at $3 \mathrm{~L} \cdot \mathrm{min}^{-1}$ via nasal prongs. Once the loading dose of the study drug was started, spinal anesthesia was obtained in the sitting position using $0.75 \%$ hyperbaric bupivacaine $12.75 \mathrm{mg}$ and fentanyl 10 $\mu \mathrm{g}$. The anesthesiologist providing care for the patient continually assessed the intraoperative level of sedation and targeted a moderate level of sedation defined by the $\mathrm{ASA}^{15}$ (i.e., depression of consciousness with maintenance of purposeful responses to verbal commands/ light tactile stimulation, an unassisted patent airway, adequate spontaneous ventilation, and cardiovascular function). Intravenous midazolam 0-4 $\mathrm{mg}$ was available to both groups intraoperatively in order to achieve this goal, and no other intraoperative narcotics or sedatives were to be used. Phenylephrine and ephedrine were available at the discretion of the anesthesiologist in the event of hemodynamic changes. Although there were no specific hemodynamic targets with respect to the administration of phenylephrine and ephedrine, all anesthesiologists were informed of the potential for bradycardia and hypotension with dexmedetomidine and were instructed to provide hemodynamic support as per their clinical judgement. No peripheral nerve blocks were performed on the study subjects, and the surgeons did not administer local anesthetic infiltration during the procedures.

Postoperatively, the infusion was discontinued once the final dressing was applied. Patients were then transferred to the PACU and PCA was initiated. Delivery of morphine was standardized to $1.5 \mathrm{mg}$ with a lockout of eight minutes. This PCA setting differs from our initial protocol registered with clinicaltrials.gov to account for convenience of using the institution's standardized PCA order forms. This decision was made prior to patient enrolment, and all patients enrolled in the study received the same PCA orders. No supplemental analgesics were ordered for the first $24 \mathrm{hr}$ following surgery. Dimenhydrinate $50 \mathrm{mg}$ and ondansetron $4 \mathrm{mg}$ were available if a patient experienced postoperative nausea or vomiting. Patients were discharged from the PACU once discharge criteria were met as per the modified Aldrete scoring system. ${ }^{16}$

All patient data and satisfaction scores were collected for $24 \mathrm{hr}$ postoperatively by a research member who was blinded to the group assignment and not involved with the perioperative or postoperative care of the patient. Patient satisfaction was assessed by directly asking the patients to rate their satisfaction with the adequacy of analgesia in the last $24 \mathrm{hr}$ as excellent, good, acceptable, or poor. Nursing staff blinded to group allocation assessed and recorded the VAS scores.

\section{Statistical analysis}

Statistical analysis was performed using SigmaPlot ${ }^{\circledR}$ version 13.0 (Systat Software Inc., San Jose, CA, USA).

Sample size was calculated using a previously published study in which mean [standard deviation (SD)] 24-hr morphine consumption for total knee arthroplasty was 58.6 (27.3) mg. ${ }^{17}$ A $50 \%$ reduction in morphine consumption was considered clinically significant as well as consistent with previously published studies showing decreased use of opioid analgesics following a dexmedetomidine infusion in patients undergoing general anesthesia. ${ }^{12}$ Using a twosided test with an alpha of 0.05 and a power of 0.9 , the required sample size for a two-sample comparison of means was estimated at 19 patients per group. The decision was made to enrol 20 patients per group to allow for potential patients who drop out.

Data were tested for normality using the Shapiro-Wilk test with a cut-off of 0.05 . Student's $t$ tests were used to analyze the outcomes in data with normal distribution, including our primary outcome. The Mann-Whitney U test 




Fig. 1 Flow diagram of screened, excluded, and recruited patients

was used for data that were not normally distributed, and a Wilcoxon rank-sum test was used to analyze patient satisfaction.

\section{Results}

In May 2014, 49 consecutive patients undergoing total knee arthroplasty were approached for enrolment in this study. Patient flow is depicted in the CONSORT diagram (Fig. 1). Nine patients were excluded from the study. Seven patients preferred a general anesthetic, one patient had an allergy to morphine, and one patient was taking opioids. Twenty patients were enrolled in each of the dexmedetomidine and placebo groups. Spinal anesthesia could not be performed on one patient in the placebo group due to difficulty finding the intrathecal space. This patient received a general anesthetic but was included in the intention-to-treat analysis. This patient's age (65 yr) and 24-hr morphine use $(62 \mathrm{mg})$ was similar to that of the overall placebo group. Patient demographics and duration of surgery were similar between both groups (Table 1).
There was no difference in the mean (SD) dose of

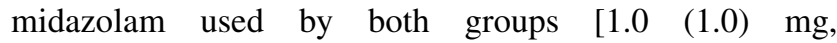
dexmedetomidine group vs 1.5 (1.2) mg, placebo group:; $P=0.153]$.

With respect to the primary outcome, the mean (SD) cumulative morphine at $24 \mathrm{hr}$ in the dexmedetomidine group was 29.2 (11.2) $\mathrm{mg}$ compared with 61.2 (17.2) $\mathrm{mg}$ in the placebo group (mean difference, $32.0 \mathrm{mg} ; 95 \%$ confidence interval [CI], 22.7 to $41.2 ; P<0.001)$. The mean (SD) morphine consumption at six hours in the dexmedetomidine group was 6.5 (5.1) $\mathrm{mg}$ compared with $14.6(8.4) \mathrm{mg}$ in the placebo group (mean difference, 8.1 $\mathrm{mg} ; 95 \% \mathrm{CI}, 3.6$ to $12.6 ; P<0.001)$. At $12 \mathrm{hr}$ postoperatively, the mean (SD) morphine use in the dexmedetomidine group was 16.0 (6.8) $\mathrm{mg}$ compared with 29.2 (10.9) $\mathrm{mg}$ in the placebo group (mean difference, $18.1 \mathrm{mg}$; $95 \%$ CI, 12.9 to $23.3 ; P<0.001$ ) (Fig. 2).

The mean (SD) time to first analgesic request was delayed in the dexmedetomidine group compared with the placebo group [240 (77) $\min v s 166$ (70) min, respectively; mean difference, $74 \mathrm{~min} ; 95 \% \mathrm{CI}, 27$ to $121 ; P=0.003$ ] (Table 2). There were no significant differences in VAS 
Table 1 Patient demographics and intraoperative characteristics Continuous values are represented by mean (SD)

\begin{tabular}{lcc}
\hline & $\begin{array}{l}\text { Dexmedetomidine } \\
\text { group }(n=20)\end{array}$ & $\begin{array}{l}\text { Placebo group } \\
(n=20)\end{array}$ \\
\hline Age & $66.2(11.4)$ & $66.1(8.6)$ \\
Sex, Female & $16(80 \%)$ & $12(60 \%)$ \\
BMI & $34.3(6)$ & $36.3(7.2)$ \\
ASA & & \\
I & 0 & $2(10 \%)$ \\
II & $12(60 \%)$ & $12(60 \%)$ \\
III & $8(40 \%)$ & $6(30 \%)$ \\
Pain at rest & $1.8(2)$ & $1.9(2.3)$ \\
Pain with movement & $5.1(2.4)$ & $5.3(2.6)$ \\
Medical Comorbidities & & $3(15 \%)$ \\
Sleep Apnea & $1(5 \%)$ & $1(5 \%)$ \\
CAD & $2(10 \%)$ & $1(5 \%)$ \\
CVD & 0 & 0 \\
COPD & $1(5 \%)$ & 0 \\
Asthma & $1(5 \%)$ & $76.8(10.8)$ \\
Heart rate (baseline) & $76.8(9.2)$ & $102.4(10.9)$ \\
beats·min & & \\
Mean arterial pressure & $99.8(9.9)$ & $59.6(15.2)$ \\
(baseline) mmHg & & \\
Surgical time (min) & $63.8(8.9)$ & \\
\hline Categoricat variabs arepro & \\
\hline
\end{tabular}

Categorical variables are represented by $n(\%)$. Heart rate and mean arterial pressure were measured prior to entering the operating room. ASA $=$ American Society of Anesthesiologists physical status classification; $\mathrm{BMI}=$ body mass index; $\mathrm{CAD}=$ coronary artery disease; $\mathrm{COPD}=$ chronic obstructive pulmonary disease; $\mathrm{CVD}=$ cerebrovascular disease

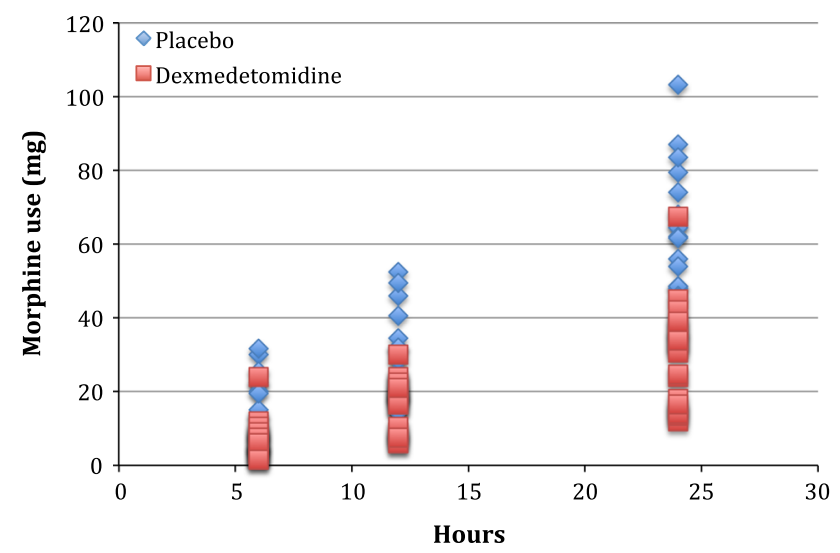

Fig. 2 Mean morphine consumption in the dexmedetomidine group at six hours was $6.5 \mathrm{mg} v s 14.6 \mathrm{mg}$ in the placebo group. At $12 \mathrm{hr}$, the mean consumption in the dexmedetomidine group was $16 \mathrm{mg} v \mathrm{~s} 29.2$ $\mathrm{mg}$ in the placebo group. At $24 \mathrm{hr}$, the mean consumption in the dexmedetomidine group was $29.2 \mathrm{mg} v s 61.2 \mathrm{mg}$ in the placebo group

scores at six, 12, or $24 \mathrm{hr}$ (Table 2). Time to discharge from the PACU was delayed in the dexmedetomidine group compared with the placebo group [163 (52) min vs
116 (46) min, respectively; mean difference, $47 \mathrm{~min}$; 95\% CI, 16 to $78 ; P=0.004]$ (Table 2). Patient satisfaction with their quality of analgesia at $24 \mathrm{hr}$ was found to be significantly higher in the dexmedetomidine group $(P=$ 0.019) (Table 2).

Intraoperatively, there were no hemodynamic differences between the two groups, with similar lowest mean arterial pressure (MAP) and heart rate. There were also no differences in estimated blood loss or amount of intravenous fluid given perioperatively (Table 3). Nevertheless, in the PACU, patients in the dexmedetomidine group were found to have a lower MAP compared with those in the placebo group; heart rate was maintained across both groups (Table 3 ). In the PACU, there was no difference between groups in the number of patients with hypotension (i.e., $>20 \%$ drop in MAP from baseline) or in the number of patients receiving phenylephrine or ephedrine (Table 3). No patient in either group had an episode of oxygen desaturation (i.e., $<92 \%$ ), either intraoperatively or in the PACU. There were more postoperative opioid-related side effects observed in the placebo group, including more nausea, vomiting, and pruritus (Table 2).

\section{Discussion}

In this RCT, patients receiving intravenous dexmedetomidine for procedural sedation during total knee arthroplasty under spinal anesthesia showed a significant reduction in postoperative opioid use in the first $24 \mathrm{hr}$ following surgery. Our 24-hr morphine reduction of $32 \mathrm{mg}$ (95\% CI, 22.7 to 41.2), which was 53\% less than that in the placebo group, is comparable with previous studies showing less postoperative opioid consumption in patients receiving dexmedetomidine infusions during general anesthesia. ${ }^{12}$ This reduction is also comparable with other modalities previously studied during total knee arthroplasty, for example, a $50 \%$ decrease in the use of periarticular infiltration. ${ }^{18}$ This 24 -hr reduction in morphine use is similar to that using a single-shot femoral nerve block with a sciatic block. This approach was reported in a recent meta-analysis of femoral nerve blocks highlighting morphine reductions from a single-shot femoral nerve block (20-mg reduction), a single-shot femoral nerve block with a sciatic block (31-mg reduction), and a continuous femoral nerve block (15-mg reduction). ${ }^{19}$

The decrease in morphine use in the dexmedetomidine group in the first $24 \mathrm{hr}$ is clinically relevant for a number of reasons. Total knee arthroplasty is an operation associated with significant postoperative pain. Actually, $60 \%$ of patients describe the postoperative pain as severe. ${ }^{13}$ Opioids typically play a large role in the treatment of 
Table 2 Secondary outcomes

\begin{tabular}{|c|c|c|c|c|c|}
\hline & Dexmedetomidine & Placebo & Mean difference & 95\% Confidence intervals & $P$ value \\
\hline Time in recovery unit (min) & $162.6(51.8)$ & 115.7(45.9) & 46.9 & (15.5 to 78.2$)$ & 0.004 \\
\hline Time to first PCA request (min) & $239.5(77.3)$ & $165.5(69.8)$ & 74.0 & (26.9 to 121.1 ) & 0.003 \\
\hline Postoperative VAS score at $6 \mathrm{hr}$ & $4.4(2.7)$ & $5.0(1.8)$ & -0.6 & $(-2.1$ to 0.90$)$ & 0.410 \\
\hline Postoperative VAS score at $12 \mathrm{hr}$ & $4.3(2.0)$ & $5.1(1.6)$ & -0.9 & $(-2.1$ to 0.4$)$ & 0.170 \\
\hline Postoperative VAS score at $24 \mathrm{hr}$ & $4.8(2.4)$ & $5.0(2.3)$ & -0.2 & $(-1.7$ to 1.3$)$ & 0.790 \\
\hline Itchiness (first $24 \mathrm{hr}$ ) & $1(5 \%)$ & $6(30 \%)$ & Odds ratio: 0.12 & $(0.01$ to 1.14$)$ & 0.015 \\
\hline Nausea + vomiting (first $24 \mathrm{hr}$ ) & $1(5 \%)$ & $7(35 \%)$ & Odds ratio:0.09 & $(0.01$ to 0.89$)$ & 0.005 \\
\hline Excellent patient satisfaction with analgesia & 4 & 0 & & & \\
\hline Good patient satisfaction with analgesia & 7 & 5 & & & \\
\hline Acceptable patient satisfaction with analgesia & 6 & 7 & & & \\
\hline Poor patient satisfaction with analgesia & 3 & 8 & & & \\
\hline
\end{tabular}

Continuous values are represented by mean $(\mathrm{SD})$. Categorical variables are represented by $n(\%) . \mathrm{PCA}=$ patient-controlled analgesia; VAS $=$ visual analogue scale

Table 3 Hemodynamic variables intraoperatively and postoperatively

\begin{tabular}{llll}
\hline & Dexmedetomidine & Placebo & $P$ value \\
\hline Lowest MAP (mmHg) intraoperatively & $76.3(10.3)$ & $79(14.6)$ & 0.511 \\
Lowest heart rate (beats· min $^{-1}$ ) intraoperatively & $60.4(8.7)$ & $62.2(10.9)$ & $2(10 \%)$ \\
Bradycardia intraoperatively & $6(30 \%)$ & $77.1(13.9)$ & 0.556 \\
Lowest MAP (mmHg) in PACU & $64.5(9.0)$ & $13(65 \%)$ & 0.051 \\
Hypotension in PACU & $17(85 \%)$ & $58.4(8.8)$ & 0.002 \\
Lowest heart rate (beats· min $^{-1}$ ) in PACU & $57.7(7.3)$ & $7(40 \%)$ & 0.787 \\
Bradycardia in PACU & $6(30 \%)$ & $7(35 \%)$ & 0.361 \\
Phenylephrine/ephedrine use & $6(30 \%)$ & $212.7(192.8)$ & 0.639 \\
Estimated intraoperative blood loss (mL) & $182.0(165.1)$ & $1,251.3(395.2)$ & 0.591 \\
Intraoperative intravenous fluid administered $(\mathrm{mL})$ & $1,490.0(390.2)$ & 0.062 \\
\hline
\end{tabular}

Continuous values are represented by mean (SD). Categorical variables are represented by $n(\%)$. Bradycardia was defined as heart rate $<55$ beats $\min ^{-1}$. Hypotension defined as a $20 \%$ drop in mean arterial pressure from patient's baseline. MAP $=$ mean arterial pressure; PACU $=$ postanesthesia care unit

postoperative pain after total knee arthroplasty, which may place patients at increased risk of postoperative respiratory depression. ${ }^{20}$ In a recent closed claims analysis of postoperative opioid-induced respiratory depression, Lee et al. make note that $88 \%$ of closed claims involving postoperative opioid-induced respiratory depression events occurred within $24 \mathrm{hr}$ of the surgical procedure. ${ }^{21}$ As well, Chung et al. found that, during the first postoperative night, increases in the central apnea index and obstructive apnea index in non-obstructive sleep apnea patients are correlated with the first 24-hr opioid requirement. ${ }^{22}$ To compound this issue, recent data have shown that the increasing demand for total knee arthroplasty appears to be linked to obesity, ${ }^{23}$ thereby placing these patients at even greater risk of adverse respiratory events. ${ }^{24}$ Lessening postoperative opioid use not only decreases opioid-related side effects ${ }^{25}$ but may also decrease the risk of postoperative respiratory depression. ${ }^{26}$
Morphine consumption was significantly reduced during all three cumulative time intervals (six, 12, and $24 \mathrm{hr}$ ). This suggests that the analgesic effect of dexmedetomidine is present throughout the first $24 \mathrm{hr}$ and that the analgesic benefits of dexmedetomidine extend past its biological half-life of two hours. ${ }^{27}$

The significant increase in the time to first analgesic request in the dexmedetomidine group was consistent with the reduction in the use of morphine. This delayed analgesic request parallels the delay in patients receiving dexmedetomidine during general anesthesia. ${ }^{28}$ It is important to emphasize that, although the level of sedation was measured in the operating room as well as in the PACU, in every case, the first analgesic demand occurred on the ward via PCA where the patient's level of sedation was not measured.

It is also interesting to point out that VAS scores were not significantly different between both groups, even 
though the increased morphine consumption in the placebo group would suggest they were experiencing more pain than those in the dexmedetomidine group. This may be explained by the patient's proper use of their PCA, as they were instructed to use the PCA to achieve a VAS score of $<4$.

Patient satisfaction with analgesia in the first $24 \mathrm{hr}$ was significantly higher in the dexmedetomidine group, which may be due to the decrease in opioid-related side effects, in particular, significantly less nausea and vomiting. The decrease in opioid-related adverse effects observed in our study is supported by similar results in a recent metaanalysis. ${ }^{6}$

One potential limitation to the widespread use of dexmedetomidine may be a delayed discharge from the PACU. We recognize that this delay could lead to inefficiencies in postoperative patient disposition and operating room flow. The primary reason for this delayed discharge can be attributed to the MAP in the dexmedetomidine group observed in the PACU. Although the delay in PACU discharge time is significant, an evaluation is needed to determine whether the benefits of decreased opioid use in the first $24 \mathrm{hr}$ outweigh the slower turnover period in the PACU, especially with respect to patients with opioid sensitivities.

As per discharge criteria at our institution, patients' MAPs must return to within $20 \%$ of their preoperative baseline prior to PACU discharge. Although there were no statistically significant differences between the two groups in the number of patients whose MAP fell $>20 \%$ below baseline, the dexmedetomidine group had a significantly lower overall mean MAP in the PACU and took longer for their MAP to return to within $20 \%$ of baseline. The hypotension observed in the PACU was likely potentiated by the direct pharmacological effects of dexmedetomidine as well as its ability to increase the level of sensory blockade during spinal anesthesia. ${ }^{29}$

In our experience, the effect of dexmedetomidine on lowering MAP was expected. Nevertheless, our results were inconsistent with a previous meta-analysis suggesting that the use of dexmedetomidine during spinal anesthesia did not show significant hemodynamic differences. ${ }^{30}$ This discrepancy with our study may be explained by the fact that the previous meta-analysis contained a combination of major and minor surgeries not associated with significant blood loss. Furthermore, the hypotension seen in the PACU in our study may have been compounded by deflating the tourniquet at the end of the surgery.

It is important to emphasize that there were no differences observed between the groups regarding the administration of phenylephrine or ephedrine for intraoperative hypotension. Our protocol did not allow for adjustment of the dose of the study infusion in the case of hemodynamic changes, and therefore, some patients may have had fewer hemodynamic changes in the PACU if they had smaller doses intraoperatively. Further doseranging studies should be performed to determine the optimal dose of dexmedetomidine that would offer the opioid-sparing benefits observed in our study while avoiding delayed discharge times and the hemodynamic changes seen in the PACU.

A limitation of our study was that the patients' level of sedation was not measured on the ward. It may be that patients in the dexmedetomidine group used less morphine due to their increased level of sedation. This seems unlikely to us since opioid consumption was decreased in all time intervals (six, 12, and $24 \mathrm{hr}$ postoperatively). If sedation had played a major role, we would expect a greater reduction in opioid use during the first time interval, in keeping with the biological half-life of dexmedetomidine. ${ }^{27}$ Furthermore, patients met Aldrete's discharge criteria of being "wide awake" prior to being transferred from the PACU to the ward. The end result of similar VAS scores between groups suggests that patients were aware of their perceived pain enough to know when to use their PCA and were not too sedated to do so.

Another limitation of this study was the lack of use of local anesthetics and other non-opioid pharmacological interventions administered in the postoperative period. Future studies comparing dexmedetomidine with other modalities as well as studies including dexmedetomidine with multimodal analgesic regiments would allow us to assess whether dexmedetomidine can be used either to enhance the analgesic effects of certain techniques or to be used in lieu of other methods.

In conclusion, we found that the use of dexmedetomidine for procedural sedation in patients undergoing total knee arthroplasty reduces opioid use postoperatively in the first $24 \mathrm{hr}$. The importance of multimodal regimens in providing superior analgesia, while limiting side effects and adverse events, is highlighted in the American Society of Anesthesiologists "Practice guidelines for acute pain management in the perioperative setting" ${ }^{31}$ It is our view that dexmedetomidine could contribute to this goal, as it offers analgesia with the benefit of providing procedural sedation without respiratory depression. Further research is needed to evaluate whether the opioid-sparing effects observed in patients undergoing total knee arthroplasty can be replicated in other types of painful surgeries performed under spinal anesthesia as well as in chronic pain patients or in patients previously taking opioids.

Author contributions: Ian A. Chan, Jurgen G. Maslany, Kyle J. Gorman, William P. McKay, and Jennifer M. O'Brien were involved in the study design and interpretation of data. Jennifer M. O'Brien 
was involved in the acquisition of data. Ian A. Chan was involved in patient recruitment, data collection, and writing the first draft of this paper. William P. McKay was involved in the analysis of data. Jurgen G. Maslany, Kyle J. Gorman, Jennifer M. O'Brien, and William P. McKay were involved in revising the article.

Conflicts of interest None declared.

\section{Disclosures None.}

Funding This work was supported by the University of Saskatchewan's Department of Anesthesiology.

\section{References}

1. Hohener D, Blumenthal $S$, Borgeat A. Sedation and regional anaesthesia in the adult patient. Br J Anaesth 2008; 100: 8-16.

2. Bhananker SM, Posner KL, Cheney FW, Caplan RA, Lee LA, Domino $K B$. Injury and liability associated with monitored anesthesia care: a closed claims analysis. Anesthesiology 2006; 104: 228-34.

3. Bhana N, Goa KL, McClellan KJ. Dexmedetomidine. Drugs 2000; 59: 263-8.

4. Kaygusuz K, Gokce G, Gursoy S, Ayan S, Mimaroglu C, Gultekin $Y$. A comparison of sedation with dexmedetomidine or propofol during shockwave lithotripsy: a randomized controlled trial. Anesth Analg 2008; 206: 114-9.

5. Ustun $Y$, Gunduz $M$, Erdogan $O$, Benlidayi $M E$. Dexmedetomidine versus midazolam in outpatient third molar surgery. J Oral Maxillofac Surg 2006; 9: 1353-8.

6. Asmussen S, Maybauer DM, Fraser J, Jennings $K$, George $S$, Maybauer MO. A meta-analysis of analgesic and sedative effects of dexmedetomidine in burn patients. Burns 2013; 39: 625-31.

7. Schnabel A, Meyer-Friebem CH, Reichl SU, Zahn PK, PogatzkiZahn EM. Is intraoperative dexmedetomidine a new option for postoperative pain treatment? A meta-analysis of randomized controlled trials. Pain 2013; 154: 1140-9.

8. Chau D, Walker V, Pai L, Cho LM. Opiates and elderly: use and side effects. Clin Interv Aging 2008; 3: 273-8.

9. Chung SA, Yuan H, Chung F. A systemic review of obstructive sleep apnea and its implications for anesthesiologists. Anesth Analg 2008; 107: 1543-63.

10. Kaya FN, Yavascaoglu B, Turker $G$, et al. Intravenous dexmedetomidine, but not midazolam, prolongs bupivacaine spinal anesthesia. Can J Anesth 2010; 57: 39-45.

11. Abdallah F, Abrishami A, Brull R. The facilitatory effects of intravenous dexmedetomidine on the duration of spinal anesthesia: a systematic review and meta-analysis. Anesth Analg 2013; 117: 271-8.

12. Gurbet A, Basagan-Mogol E, Turker G, Ugun F, Kaya FN, Ozcan $B$. Intraoperative infusion of dexmedetomidine reduces perioperative analgesic requirements. Can J Anesth 2006; 53: 646-52.

13. Bonica JJ. Postoperative pain. In: Bonica JJ, Loeser JD, Chapman CR, Fordyce WE, editors. The Management of Pain. 2nd ed. Philadelphia: Lea and Febiger; 1990. p. 461-80.
14. Krutz S, Ong K, Lau E, Mowat F, Halpern M. Projections of primary and revision hip and knee arthroplasty in the United States from 2005 to 2030. J Bone Joint Surg Am 2007; 89: 780-5.

15. American Society of Anesthesiologists Task Force on Sedation, Analgesia by Non-Anesthesiologists. Practice guidelines for sedation and analgesia by non-anesthesiologists. Anesthesiology 2002; 96: 1004-17.

16. Aldrete JA. The post-anesthesia recovery score revisited. J Clin Anesth 1995; 7: 89-91.

17. Mauerhan DR, Campbell M, Miller JS, Mokris JG, Gregory A, Kiebzak GM. Intra-articular morphine and/or bupivacaine in the management of pain after total knee arthroplasty. J Arthroplasty 1997; 12: 546-52.

18. Essving $P$, Axelsson $K$, Aberg E, et al. Local infiltration analgesia versus intrathecal morphine for postoperative pain management after total knee arthroplasty: A randomized controlled trial. Anesth Analg 2011; 113: 926-33.

19. Paul J, Arya A, Hurlburt L, et al. Femoral nerve block improves analgesia outcomes after total knee arthroplasty: a meta-analysis of randomized controlled trials. Anesthesiology 2010; 113: 114462.

20. Hagle ME, Lehr VT, Brubakken K. Shippee A Respiratory depression in adult patients with intravenous patient-controlled analgesia. Orthop Nurs 2004; 23: 18-27.

21. Lee LA, Caplan RA, Stephens LS, et al. Postoperative opioidinduced respiratory depression: a closed claims analysis. Anesthesiology 2015; 122: 659-65.

22. Chung F, Liao $P$, Yegneswaran B, Shapiro CM, Kang $W$. Postoperative changes in sleep-disordered breathing and sleep architecture in patients with obstructive sleep apnea. Anesthesiology 2014; 120: 287-98.

23. Derman PB, Fabricant PD, David G. The role of overweight and obesity in relation to the more rapid growth of total knee arthroplasty volume compared with total hip arthroplasty volume. J Bone Joint Surg Am 2014; 96: 922-8.

24. Namba $R$, Paxton L, Fithian D, Stone $M L$. Obesity and perioperative morbidity in total hip and total knee arthroplasty patients. J Arthroplasty 2005; 20(7 Suppl 3): 46-50.

25. Benyamin $R$, Trescot AM, Datta $S$, et al. Opioid complications and side effects. Pain Physician 2008; 11(2 Suppl): S105-20.

26. Pattinson KT. Opioids and the control of respiration. Br J Anaesth 2008; 100: 747-58.

27. Precedex [package insert]. Lake Forest, IL: Hospira, Inc; 2008.

28. Ohtani $N$, Yasui Y, Watanabe D, Kitamura M, Shoji K, Masaki E. Perioperative infusion of dexmedetomidine at a high dose reduces postoperative analgesic requirements: a randomized control trial. J Anesth 2011; 25: 872-8.

29. Annamalai A, Singh S, Singh A, Mahrous DE. Can intravenous dexmedetomidine prolong bupivacaine intrathecal spinal anesthesia? J Anesth Clin Res 2013; 4: 372.

30. Niu XY, Dding XB, Guo T, Chen MH, Fu SK, Li Q. Effects of intravenous and intrathecal dexmedetomidine in spinal anesthesia: a meta-analysis. CNS Neurosci Ther 2013; 19: 897904.

31. American Society of Anesthesiologists Task Force on Acute. Pain Management. Practice guidelines for acute pain management in the perioperative setting: an updated report by the Society of Anesthesiologists Task Force on Acute Pain Management. Anesthesiology 2012; 116: 248-73. 